\section{(A) Check for updates}

Cite this: Dalton Trans., 2021, 50, 722

\title{
Structural and electronic studies of substituted $m$-terphenyl lithium complexes $\uparrow$
}

\author{
Andrew J. Valentine, (DD a Ana M. Geer, (D) ${ }^{\mathrm{b}}$ Laurence J. Taylor, (ID a \\ Andrew M. Teale, (D) ${ }^{a}$ Katherine E. Wood, ${ }^{a}$ Huw E. L. Williams, (D) William Lewis, (D) ${ }^{d}$ \\ Stephen P. Argent, (D) a Jonathan McMaster (D) *a and Deborah L. Kays (D)*a
}

\begin{abstract}
The effect of para-substitution upon the structural and electronic properties of a series of $m$-terphenyl lithium complexes $\left[\mathrm{R}-\mathrm{Ar}^{\#}-\mathrm{Li}\right]_{2}\left(\mathrm{R}=t-\mathrm{Bu}\right.$ 1, $\mathrm{SiMe}_{3} \mathbf{2}, \mathrm{H} \mathrm{3}, \mathrm{Cl}$ 4, $\mathrm{CF}_{3}$ 5; where $\mathrm{R}-\mathrm{Ar}^{\#}=2,6-\{2,6-\mathrm{Xyl}\}_{2}-4-$ $\mathrm{R}-\mathrm{C}_{6} \mathrm{H}_{2}$ and $2,6-\mathrm{Xyl}=2,6-\mathrm{Me}_{2} \mathrm{C}_{6} \mathrm{H}_{3}$ ) has been investigated. $\mathrm{X}$-ray crystallography reveals the complexes to be structurally similar, with little variation in $\mathrm{C}-\mathrm{M}-\mathrm{C}$ bond lengths and angles across the series. However, in-depth NMR spectroscopic studies reveal notable electronic differences, showing a linear correlation between the ${ }^{7} \mathrm{Li}\left\{{ }^{1} \mathrm{H}\right\}$ NMR chemical shifts of the para-substituted complexes and their Hammett constants. The flanking methyl protons exhibit a similar electronic shift in the ${ }^{1} \mathrm{H}$ NMR spectra, which has been rationalised by the presence of through-space $\mathrm{Li}$...H interactions, as evidenced by two-dimensional ${ }^{7} \mathrm{Li}-{ }^{1} \mathrm{H}$ heteronuclear Overhauser spectroscopy (HOESY). In both cases, electron-withdrawing substituents are found to cause an upfield peak shift. A computational analysis is employed to account for these trends.
\end{abstract}

Received 19th November 2020 Accepted 3rd December 2020 DOI: 10.1039/d0dt03972a rsc.li/dalton

\section{Introduction}

The development of sterically demanding ligand systems has become a central research theme for the stabilisation of lowcoordinate metal complexes. One important example is the $m$-terphenyl ligand, which has been repeatedly utilised in the isolation of low-coordinate main group and transition metal complexes. ${ }^{1-6}$ Although a plethora of $m$-terphenyl frameworks have been designed, most studies have been structurally focused, aimed at investigating the effects of steric bulk on the geometries, bonding modes, and reactivities of the resulting compounds. $^{7-18}$

For instance, the solid state structures observed for a series of $m$-terphenyl lithium complexes vary depending on the steric demands of the flanking ortho-aryl substituents. ${ }^{19,20}$

\footnotetext{
${ }^{a}$ School of Chemistry, University of Nottingham, University Park, Nottingham, NG7 2RD, UK. E-mail: Deborah.Kays@nottingham.ac.uk,

Jonathan.McMaster@nottingham.ac.uk

${ }^{b}$ Departamento de Química Inorgánica, Instituto de Síntesis Química y Catálisis Homogénea (ISQCH), CSIC, Universidad de Zaragoza, Pedro Cerbuna 12, 50009 Zaragoza, Spain

${ }^{c}$ Centre for Biomolecular Sciences, University of Nottingham, University Park, Nottingham, NG7 2RD, UK

${ }^{d}$ School of Chemistry, The University of Sydney, F11, Eastern Ave, Sydney, NSW 2006, Australia

$\dagger$ Electronic supplementary information (ESI) available. CCDC 2045214-2045221. For ESI and crystallographic data in CIF or other electronic format see DOI: 10.1039/d0dt03972a
}

Increasing the steric bulk of $2,6-\mathrm{Ar}_{2} \mathrm{C}_{6} \mathrm{H}_{3} \mathrm{Li}$ alters its aggregation state from a dimer, ${ }^{19}$ to a more crowded dimer featuring $\eta^{6}$-arene coordination of the flanking aryl groups, ${ }^{20}$ to a monomer stabilised by a coordinated molecule of benzene, ${ }^{20}$ for $\mathrm{Ar}=\operatorname{Mes}\left(2,4,6-\mathrm{Me}_{3} \mathrm{C}_{6} \mathrm{H}_{2}\right)$, Dipp (2,6-i- $\left.-\mathrm{Pr}_{2} \mathrm{C}_{6} \mathrm{H}_{3}\right)$ and Tripp (2,4,6-i- $\left.\mathrm{Pr}_{3} \mathrm{C}_{6} \mathrm{H}_{2}\right)$ respectively. ${ }^{5,6}$

However, less work has been reported on varying the electronic effects of these $m$-terphenyl systems, with studies limited mainly to a handful of main group complexes ${ }^{21-25}$ and the quintuply-bonded $\mathrm{Cr}-\mathrm{Cr}$ dimer $\left[\left(2,6-\mathrm{Dipp}_{2}-4-\mathrm{R}-\mathrm{C}_{6} \mathrm{H}_{2}\right) \mathrm{Cr}\right]_{2}$ $\left(\mathrm{R}=\mathrm{H}, \mathrm{SiMe}_{3}, \mathrm{OMe}, \mathrm{F}\right) .{ }^{26}$ Even their lithium precursors, while structurally characterised, have not been studied from an electronic viewpoint. Therefore, it is the objective of this research to develop a toolbox of $m$-terphenyl ligands featuring a range of para-substituents (R) to investigate the electronic effects of substitution upon their metal complexes.

To this end, a series of para-substituted $m$-terphenyl lithium complexes $\left[\mathrm{R}-\mathrm{Ar}^{\#}-\mathrm{Li}\right]_{2}\left(\mathrm{R}-\mathrm{Ar}^{\#}=2,6-\left\{2,6-\mathrm{Xyl}_{2}-4-\mathrm{R}_{-} \mathrm{C}_{6} \mathrm{H}_{2}\right.\right.$; $\mathrm{R}=t-\mathrm{Bu}, \mathrm{SiMe}_{3}, \mathrm{Cl}, \mathrm{CF}_{3} ; 2,6-\mathrm{Xyl}=2,6-\mathrm{Me}_{2} \mathrm{C}_{6} \mathrm{H}_{3}$ ) are reported, and discussed alongside the previously published unsubstituted analogue $\left[\mathrm{H}-\mathrm{Ar}^{\#}-\mathrm{Li}\right]_{2} \cdot{ }^{27}$ The geometric and electronic structures of these compounds are elucidated through X-ray crystallographic and NMR spectroscopic studies, respectively. Specifically, ${ }^{7} \mathrm{Li}$ NMR spectroscopy is employed to assess the electronic effects directly at the metal centre, with two-dimensional ${ }^{7} \mathrm{Li}-{ }^{1} \mathrm{H}$ heteronuclear Overhauser spectroscopy (HOESY) measurements demonstrating the presence of through-space ${ }^{7} \mathrm{Li} \cdots{ }^{1} \mathrm{H}$ interactions. Computational modelling with density 
functional theory (DFT) is also employed to help rationalise the observed trends in NMR parameters across the series.

\section{Results and discussion}

\subsection{Synthesis}

A series of $m$-terphenyl iodides $\mathrm{R}-\mathrm{Ar}^{\#}-\mathrm{I}\left(\mathrm{R}=t\right.$ - $\mathrm{Bu}, \mathrm{SiMe}_{3}, \mathrm{Cl}$, $\left.\mathrm{CF}_{3}\right)^{28}$ was synthesised via similar procedures to other terphenyl compounds, ${ }^{22,25-27,29-33}$ and $\mathrm{H}-\mathrm{Ar}^{\#}-\mathrm{I}$ was obtained following a previously reported $\operatorname{method}^{15,32}$ (see ESI, section $\mathrm{S} 2 \dagger$ ). Lithium-halogen exchange reactions performed on these iodide compounds with excess $n$-butyllithium in isohexane at $0{ }^{\circ} \mathrm{C}$ afforded the $m$-terphenyl lithium complexes $\left[\mathrm{R}-\mathrm{Ar}^{\#}-\mathrm{Li}\right]_{2}$ ( $\mathrm{R}=t$-Bu 1, $\mathrm{SiMe}_{3} 2, \mathrm{H} \mathrm{3}, \mathrm{Cl}$ 4, $\left.\mathrm{CF}_{3} 5\right)$ as white powders, according to Scheme 1. A range of yields was obtained $(38 \%, 60 \%$, $99 \%$, quantitative and $95 \%$ for $\mathbf{1 - 5}$ respectively); the low yield of 1 can be ascribed to the greater solubility of the $t$-Bu substituted complex in hexane. Recrystallisation of 1, 2, 4 and 5 from a $-30{ }^{\circ} \mathrm{C}$ isohexane solution produced colourless crystals suitable for X-ray diffraction analysis. The crystal structure of 3 has previously been reported. ${ }^{27}$ Complexes 1-5 have been characterised by multinuclear $\left({ }^{1} \mathrm{H},{ }^{13} \mathrm{C}\left\{{ }^{1} \mathrm{H}\right\},{ }^{19} \mathrm{~F},{ }^{29} \mathrm{Si},{ }^{7} \mathrm{Li}\left\{{ }^{1} \mathrm{H}\right\}\right)$ NMR spectroscopies, diffusion-ordered spectroscopy (DOSY), and ${ }^{7} \mathrm{Li}-{ }^{1} \mathrm{H}$ HOESY experiments.

\subsection{Crystallographic characterisation}

Single crystal X-ray diffraction data were collected for all new iodide ligand precursors, as well as the new lithium complexes 1, 2, 4, and 5. The crystal structure of $\mathbf{1}$ is presented in Fig. 1 and full crystallographic data are provided in the ESI (section S4, Fig. S30-S32†). The crystallographic data confirms that all complexes adopt a dimeric structure featuring two anionic $m$-terphenyl units linked by two lithium cations to form a planar $\mathrm{Li}_{2} \mathrm{C}_{2}$ core (see Fig. S31, S32 and Table $\mathrm{S} 1$ in the ESI $\dagger$ ). Similar $\mathrm{Li}_{2} \mathrm{C}_{2}$ cores are observed across the series, with $\operatorname{Li}(1) \cdots \operatorname{Li}(2)$ distances of $2.304(3)-2.332(4) \AA \mathrm{C}_{\text {ipso }} \cdots \mathrm{C}_{\text {ipso }}$ distances between 3.6893(18)-3.702(3) $\AA$, and $\mathrm{C}_{\text {ipso }}-\mathrm{Li}-\mathrm{C}_{\text {ipso }}$ angles in the range of $114.59(13)-116.60(10)^{\circ}\left[\Sigma_{\mathrm{Li}-\mathrm{C}-\mathrm{Li}-\mathrm{C}}=360^{\circ}\right]$. Furthermore, all $\mathrm{C}_{i p s o}-\mathrm{Li}$ bond lengths occur within a narrow range $[2.158(3)-2.1985(18) \AA]$ and are comparable to the unsubstituted analogue 3 [2.143(5)-2.187(6) $\AA$ ] and other $m$-terphenyl lithium dimers. ${ }^{15,19,27}$

Weaker intramolecular interactions are also observed between the lithium ions and the xylyl flanking groups, with

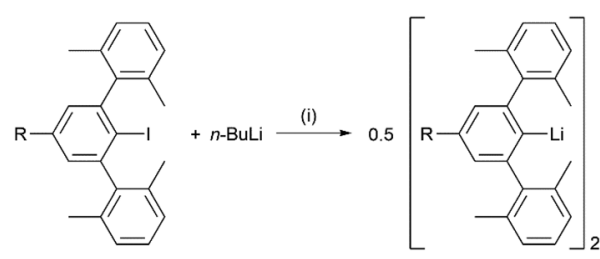

Scheme 1 Synthesis of lithium complexes $\left[R-A_{r}^{\#}-L i\right]_{2}(R=t-B u$, $\mathrm{SiMe}_{3} 2, \mathrm{H} \mathrm{3}, \mathrm{Cl} 4, \mathrm{CF}_{3}$ 5). Reaction conditions: (i) isohexane, $0{ }^{\circ} \mathrm{C}$ to room temperature, $16 \mathrm{~h},-n$-Bul.

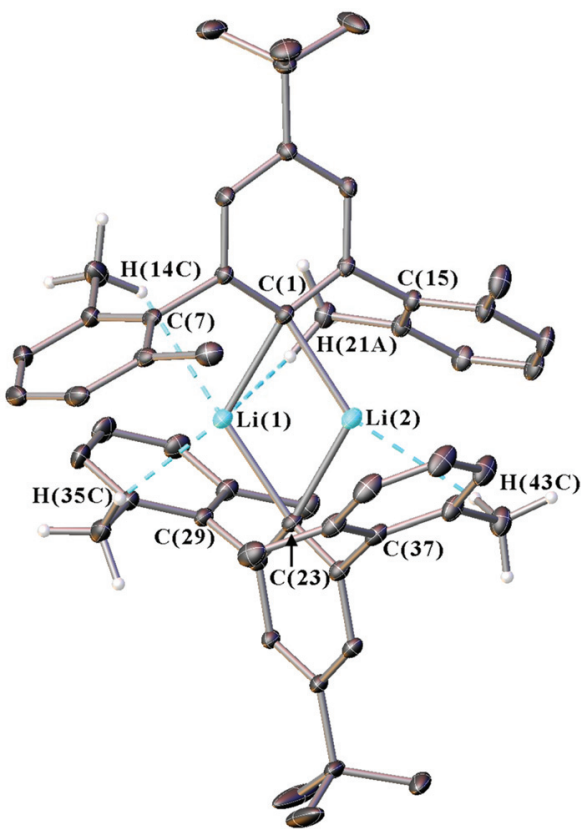

Fig. 1 Crystal structure of the $m$-terphenyl lithium complex 1 . Dashed lines indicate the short $\mathrm{Li} \cdots \mathrm{H}-\mathrm{C}$ anagostic contacts. Ellipsoids set at $40 \%$ probability, and the hydrogen atoms are placed in idealised positions for structure refinement. All non-anagostic hydrogen atoms and residual solvent molecules are omitted for clarity.

secondary contacts that are shorter than the sum of the van der Waals radii for lithium and hydrogen (3.02 $\AA$ ) or lithium and carbon $(3.52 \AA) .{ }^{34,35}$ A summary of these contacts is given in Table S2 of the ESI. $\dagger$ For complexes 1, 2, 4 and 5, the lithium ions interact with the ipso-carbons of the flanking aryls [2.4244(15)-2.729(4) $\mathrm{A}]$, and also form multiple $\mathrm{Li} \cdots \mathrm{H}-\mathrm{C}$ anagostic interactions ${ }^{36}$ with the hydrogens of the flanking methyl groups [2.338(2)-2.920(3) §].

In summary, the crystal structures of 1, 2, 4 and 5 show little structural variation as the para-substituent is changed, which suggests that the geometries of $m$-terphenyl organolithiums are dominated by steric rather than electronic factors. ${ }^{5,6,19,20}$ The structures do, however, show weak $\mathrm{Li} \cdots \mathrm{H}-\mathrm{C}$ anagostic contacts between the lithium ions and the flanking methyl groups. These interactions have been explored further in our NMR spectroscopic investigations, as discussed below.

\subsection{NMR spectroscopic characterisation}

The electronic properties of $\mathbf{1 - 5}$ were studied by ${ }^{1} \mathrm{H},{ }^{13} \mathrm{C}\left\{{ }^{1} \mathrm{H}\right\}$ and ${ }^{7} \mathrm{Li}\left\{{ }^{1} \mathrm{H}\right\}$ NMR spectroscopies in $d_{6}$-benzene. Due to their poor solubilities the solutions were saturated, except for 1 whose $t$-Bu group aided dissolution. To determine the aggregation state of the complexes in solution, DOSY experiments were performed. ${ }^{37,38}$ Whilst the unsubstituted iodide $\mathrm{H}-\mathrm{Ar}^{\#}-\mathrm{I}$ gave a hydrodynamic radius $\left(r_{\mathrm{H}}\right)$ of $3.0 \AA$, the equivalent lithium complex 3 gave a larger $r_{\mathrm{H}}$ of $4.8 \AA$, which correlates with its approximate crystallographic dimensions $(9.4 \times 9.9 \AA)$. The other para-substituted complexes yield similarly large radii that, except for $\mathbf{5}$, increase with bulkier substituents. In 
all cases, only one set of NMR spectroscopic resonances is observed, suggesting that only one aggregation state is present in solution for each of the complexes. It should be noted that the $r_{\mathrm{H}}$ values for $\mathbf{1}, \mathbf{2}, \mathbf{4}$, and $\mathbf{5}$ deviate more from the crystallographic dimensions than $\mathbf{3}$, which is likely due to the more ellipsoidal shape of the molecules (see Fig. S33, ESI $\dagger$ ). ${ }^{39}$ However, the overall increase of hydrodynamic radii for 1-5 compared to the monomeric iodide $\mathrm{H}-\mathrm{Ar}^{\#}-\mathrm{I}$ suggests that all these lithium complexes are dimeric in $d_{6}$-benzene solution. The results are summarised in Table 1.

The key ${ }^{1} \mathrm{H},{ }^{13} \mathrm{C}\left\{{ }^{1} \mathrm{H}\right\}$, and ${ }^{7} \mathrm{Li}\left\{{ }^{1} \mathrm{H}\right\}$ NMR spectroscopic signals of 1-5 are summarised in Table 2, with the numbering scheme presented in Fig. 2. The ${ }^{1} \mathrm{H}$ NMR spectra show four characteristic peaks, although in some cases the signals for the aromatic xylyl protons $(\mathrm{H}-7$ and $\mathrm{H}-8)$ overlap. Relative to the iodides $\left(\mathrm{R}-\mathrm{Ar}^{\#}-\mathrm{I}\right)$, all resonances are shifted upfield due to the greater shielding provided by the anionic ligands. A comparison of the ${ }^{1} \mathrm{H}$ NMR spectra across the series reveals three key features. Firstly, the meta-hydrogens on the central rings exhibit small variations in chemical shift $(\mathrm{H}-3=6.85,7.04$, $6.77,6.78,6.99 \mathrm{ppm}$ for $\mathbf{1 - 5}$, respectively) with no overall trend, see Table 2. Secondly, the xylyl aryl protons, H-7 (6.86-7.01 ppm) and $\mathrm{H}-8$ (6.94-7.01 ppm), remain essentially

Table 1 Diffusion coefficients, $D$, and hydrodynamic radii, $r_{\mathrm{H}}$, obtained from the DOSY measurements of the monomeric $\mathrm{H}-\mathrm{Ar}^{\#}-\mathrm{I}$ and the dimeric $\left[\mathrm{R}-\mathrm{Ar}^{\#}-\mathrm{Li}\right]_{2}(1-5)$ species. Their crystallographic diameters, $d_{\mathrm{C}^{\prime}}$ are provided for comparison

\begin{tabular}{|c|c|c|c|c|}
\hline \multirow[b]{2}{*}{ Compound $^{a}$} & \multirow{2}{*}{$\begin{array}{l}\text { Diffusion } \\
\text { coefficient, } \\
D\left(10^{-10} \mathrm{~m}^{2} \mathrm{~s}^{-1}\right)\end{array}$} & \multirow{2}{*}{$\begin{array}{l}\text { Hydrodynamic } \\
\text { radius, } r_{\mathrm{H}}(\AA)\end{array}$} & \multicolumn{2}{|c|}{$\begin{array}{l}\text { Crystallographic } \\
\text { diameters, } d_{\mathrm{c}}(\AA)\end{array}$} \\
\hline & & & Length $^{b}$ & Width $^{c}$ \\
\hline $\mathrm{H}-\mathrm{Ar}^{\#}-\mathrm{I}$ & 12.30 & 3.0 & 4.9 & 9.9 \\
\hline$\left[\mathrm{H}-\mathrm{Ar}^{\#}-\mathrm{Li}\right]_{2}(3)$ & 7.54 & 4.8 & 9.4 & 9.9 \\
\hline$\left[\mathrm{Cl}-\mathrm{Ar}^{\#}-\mathrm{Li}\right]_{2}(4)$ & 6.72 & 5.4 & 12.8 & 9.9 \\
\hline$\left[\mathrm{F}_{3} \mathrm{C}-\mathrm{Ar}^{\#}-\mathrm{Li}\right]_{2}(5)$ & 7.59 & 4.8 & 13.4 & 9.9 \\
\hline$\left[t-\mathrm{Bu}-\mathrm{Ar}^{\#}-\mathrm{Li}\right]_{2}(\mathbf{1})$ & 6.59 & 5.5 & 13.6 & 9.9 \\
\hline$\left[\mathrm{Me}_{3} \mathrm{Si}-\mathrm{Ar}^{\#}-\mathrm{Li}\right]_{2}(2)$ & 6.27 & 5.8 & 14.4 & 9.9 \\
\hline \multicolumn{5}{|c|}{$\begin{array}{l}{ }^{a} \text { All samples were prepared as } 24 \mathrm{mM} \text { solutions in } d_{6}-\mathrm{benzene} \text {. } \\
{ }^{b} \text { Length along the compound measured between } \mathrm{R} \cdots \mathrm{I}\left(\mathrm{H}-\mathrm{Ar}^{\sharp}-\mathrm{I}\right) \text { and } \\
\mathrm{R} \cdots \mathrm{R}(\mathbf{1}-\mathbf{5}) \text {, where } \mathrm{R} \text { is the outermost nucleus of the para-substituent. } \\
{ }^{c} \text { Width across the compound measured between } \mathrm{C} \cdots \mathrm{C} \text { for the outer- } \\
\text { most carbon atoms of the flanking aryl rings on each } m \text {-terphenyl } \\
\text { ligand. All widths averaged at } 9.9 \AA \text { A. }\end{array}$} \\
\hline
\end{tabular}

unshifted, suggesting that the substituent in the para-position has minimal electronic communication with the flanking aryl rings. Thirdly, the xylyl methyl protons shift upfield (H-9 = $1.83,1.81,1.80,1.61,1.55 \mathrm{ppm}$ for $1-5$, respectively) with increased electron-withdrawing strength of the para-substituent. A graph of these chemical shifts $(\delta)$ against the corresponding Hammett constants $\left(\sigma_{\text {para }}\right)^{40}$ reveals a linear correlation, see Fig. 4 (blue line; $R^{2}=0.92$ ). This trend is not observed in the respective iodide compounds $(\mathrm{H}-9=2.06,2.05$, 2.06, 2.07 and $2.02 \mathrm{ppm}$ for $\mathrm{R}-\mathrm{Ar}^{\#}-\mathrm{I}$, where $\mathrm{R}=t$-Bu, $\mathrm{SiMe}_{3}, \mathrm{H}$, $\mathrm{Cl}$ and $\mathrm{CF}_{3}$, respectively) and proceeds in the opposite direction to what one might expect, with electron-withdrawing groups causing an apparent shielding effect. This suggests that the para-substituent is exerting a direct electronic influence on the environment of the $\mathrm{H}-9$ methyl protons.

The ${ }^{13} \mathrm{C}\left\{{ }^{1} \mathrm{H}\right\}$ NMR spectra of 1-5 show nine peaks for the carbons of the ligand framework, with additional peaks for the $t$-Bu, $\mathrm{SiMe}_{3}$ and $\mathrm{CF}_{3}$ groups in 1, 2 and 5, respectively. Compared to the iodides $\left(\mathrm{R}-\mathrm{Ar}^{\#}-\mathrm{I}\right)$, the largest change is seen in the ipso-carbons, which are shifted downfield $(\mathrm{C}-1=106.9$ vs. $172.7 \mathrm{ppm}$ for $\mathrm{H}-\mathrm{Ar}^{\#}-\mathrm{I}$ and 3 , respectively) owing to a large deshielding effect in the plane perpendicular to the $\mathrm{C}-\mathrm{Li}$ bond. ${ }^{19,41-44}$ In all cases, the NMR resonances for the ipsocarbons of 1-5 were of low intensity and therefore assigned from ${ }^{1} \mathrm{H}-{ }^{13} \mathrm{C}$ HMBC spectra. For 3, a longer ${ }^{13} \mathrm{C}\left\{{ }^{1} \mathrm{H}\right\}$ NMR experiment with $\mathrm{d}_{1}$ of $10 \mathrm{~s}$ was performed to achieve better resolution of the ipso-carbon peak (Fig. 3). This revealed a seven-line splitting pattern (blue) centred at $172.7 \mathrm{ppm}$ with a $1: 2: 3: 4: 3: 2: 1$ intensity ratio $\left({ }^{1} J_{{ }^{13} \mathrm{C}^{7} \mathrm{Li}}=23.3 \mathrm{~Hz}\right)$ character-

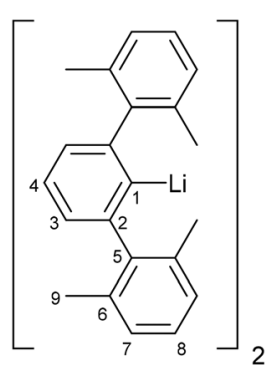

Fig. 2 NMR numbering scheme for the $m$-terphenyl lithium complexes 1-5.

Table 2 Relevant ${ }^{1} \mathrm{H},{ }^{13} \mathrm{C}\left\{{ }^{1} \mathrm{H}\right\}$ and ${ }^{7} \mathrm{Li}\left\{{ }^{1} \mathrm{H}\right\}$ NMR chemical shifts, $\delta$, for the $m$-terphenyl lithium complexes $\left[\mathrm{R}-\mathrm{Ar}^{\#}-\mathrm{Li}\right]_{2}(1-5)$. The flanking aryl atoms remain unshifted so have been omitted

\begin{tabular}{|c|c|c|c|c|c|c|c|c|c|}
\hline \multirow[b]{2}{*}[\mathrm{R}-\mathrm{Ar}^{\#}-\mathrm{Li}]{$_{2}$} & \multirow[b]{2}{*}{$\mathrm{R}$ group } & \multicolumn{7}{|c|}{${ }^{1} \mathrm{H},{ }^{13} \mathrm{C}\left\{{ }^{1} \mathrm{H}\right\}$ and ${ }^{7} \mathrm{Li}\left\{{ }^{1} \mathrm{H}\right\}$ NMR Chemical Shifts, $\delta(\mathrm{ppm})$} & \multirow[b]{2}{*}{$\mathrm{Li}$} \\
\hline & & $\mathrm{H}-3$ & $\mathrm{H}-9$ & $\mathrm{C}-1$ & $\mathrm{C}-2$ & $\mathrm{C}-3$ & C-4 & C-9 & \\
\hline 1 & $t-\mathrm{Bu}$ & 6.85 & 1.83 & 168.1 & 152.0 & 120.4 & 148.7 & 21.8 & 1.60 \\
\hline 2 & $\mathrm{SiMe}_{3}$ & 7.04 & 1.81 & 174.2 & 151.6 & 128.1 & 136.5 & 21.9 & 1.47 \\
\hline 3 & $\mathrm{H}$ & 6.77 & 1.80 & 172.7 & 152.0 & 123.6 & 126.3 & 21.8 & 1.46 \\
\hline 4 & $\mathrm{Cl}$ & 6.78 & 1.61 & 170.7 & 153.6 & 123.6 & 132.9 & 21.5 & 1.10 \\
\hline 5 & $\mathrm{CF}_{3}$ & 6.99 & 1.55 & 180.2 & 152.4 & 119.5 & $-a$ & 21.5 & 0.93 \\
\hline
\end{tabular}

${ }^{a}$ Peak C-4 for 5 not observed (obscured by $d_{6}$-benzene solvent peak). 


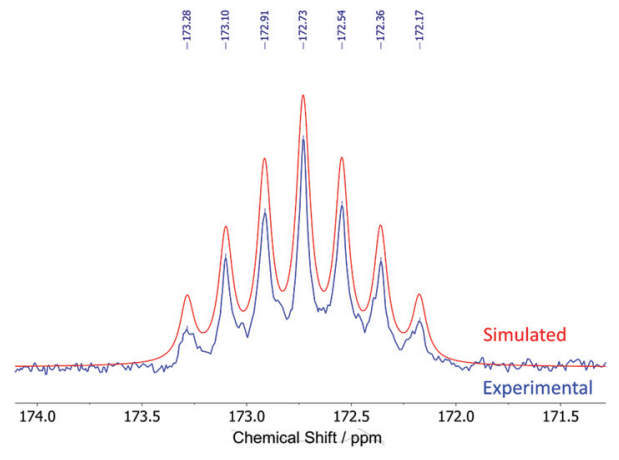

Fig. 3 Seven-line splitting pattern of the ipso-carbons in the experimental (blue) and simulated (red) ${ }^{13} \mathrm{C}\left\{{ }^{1} \mathrm{H}\right\}$ NMR spectra of $\left[\mathrm{H}-\mathrm{Ar}^{\#}-\mathrm{Li}\right]_{2}$ (3).

istic of quadrupolar coupling to two ${ }^{7} \mathrm{Li}$ nuclei $(I=3 / 2$, natural abundance: $92.41 \%)$, providing further evidence that the lithium complexes are dimeric in $d_{6}$-benzene solution. ${ }^{45-48}$ The experimental spectrum was well simulated (red, see ESI, section $\mathrm{S} 1 \dagger)$. Multiplets arising from ${ }^{6} \mathrm{Li}(I=1$, natural abundance $=7.59 \%$ ) were too low intensity to resolve experimentally.

A comparison of the ${ }^{13} \mathrm{C}\left\{{ }^{1} \mathrm{H}\right\}$ NMR spectra of $\mathbf{1 - 5}$ reveals that all ${ }^{13} \mathrm{C}$ signals of the xylyl flanking groups remain essentially unshifted across the series. The shift observed for the xylyl methyl groups in the ${ }^{1} \mathrm{H}$ NMR spectrum (H-9) is not replicated in the ${ }^{13} \mathrm{C}\left\{{ }^{1} \mathrm{H}\right\}$ NMR spectrum (C-9). The peaks for the central ring carbons vary considerably across the series (except for C-2, see Table 2): larger variations are noted for C-4 (126.3-148.7 ppm) than for C-1 (168.1-180.2 ppm) and C-3 (119.5-128.1 ppm). Though no reliable trends can be identified, a general downfield shift is observed for C-1 with increasing $\sigma_{\text {para }}$.

The ${ }^{7} \mathrm{Li}\left\{{ }^{1} \mathrm{H}\right\}$ NMR spectra of $\mathbf{1 - 5}$ also provided valuable information on the complexes. Although ${ }^{7} \mathrm{Li}$ NMR spectroscopy is typically sensitive to the analyte concentration, aggregation, and solvent effects, these factors appear to be negligible here. ${ }^{4-51}$ This was demonstrated by the spectra for the more soluble $t$-Bu complex (1) whose ${ }^{7} \mathrm{Li}\left\{{ }^{1} \mathrm{H}\right\}$ NMR resonance remains unshifted over a wide concentration range (1.60 ppm at 24, 48 and $72 \mathrm{mM}$, respectively). This may be due to the steric bulk of the ligands shielding the metal centre from the surrounding solvent. For complexes 2-5, saturated samples were used for NMR measurements due to their poor solubilities in $d_{6}$-benzene. The steric influence of the xylyl flanking groups on the lithium ions is assumed to remain consistent throughout the series and, therefore, not to contribute to changes in the ${ }^{7} \mathrm{Li}\left\{{ }^{1} \mathrm{H}\right\}$ NMR chemical shifts. This is in contrast to previous work on $m$-terphenyl lithium complexes, where changing the steric bulk of the flanking groups varies the ${ }^{7} \mathrm{Li}\left\{{ }^{1} \mathrm{H}\right\}$ NMR signal. ${ }^{15}$

In all cases, the ${ }^{7} \mathrm{Li}\left\{{ }^{1} \mathrm{H}\right\}$ NMR spectra show a single environment for the two lithium ions of the dimer. The position of these peaks shifts upfield $(1.60,1.47,1.46,1.10$ and $0.93 \mathrm{ppm}$ for 1-5, respectively) as the electron-withdrawing strength of

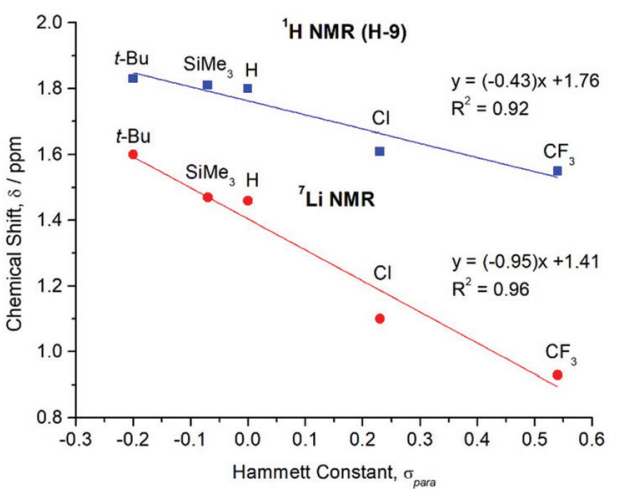

Fig. 4 Plot of the ${ }^{1} \mathrm{H}$ (for flanking methyl protons, $\mathrm{H}-9$ ) and ${ }^{7} \mathrm{Li}\left\{{ }^{1} \mathrm{H}\right\}$ NMR chemical shifts $(\delta)$ for the para-substituted lithium complexes [R$\mathrm{Ar}^{\#}-\mathrm{Li}_{2}$ (1-5) versus their corresponding literature Hammett constants $\left(\sigma_{\text {para }}\right) .{ }^{40}$

the para-substituent is increased (Table 2). Once again, plotting a graph of these chemical shifts $(\delta)$ against the Hammett constants $\left(\sigma_{\text {para }}\right)$ reveals a linear correlation, see Fig. 4 (red line; $\left.R^{2}=0.96\right){ }^{40}$ indicating a direct influence on the electronic properties of the lithium ions by the para-substituent. As with the H-9 protons, the trend is counterintuitive, since one might expect electron-withdrawing groups to deshield the nuclei and cause a downfield shift. However, a similar observation has been reported for the series of para-substituted aryllithium complexes $\left[4-\mathrm{R}-\mathrm{C}_{6} \mathrm{H}_{4}\right]_{2} \mathrm{Li}(\mathrm{R}=\mathrm{OMe}, \mathrm{Me}, \mathrm{H}, \mathrm{F}, \mathrm{Cl}$, $\left.\mathrm{CF}_{3}\right)^{52-54}$

These ${ }^{7} \mathrm{Li}\left\{{ }^{1} \mathrm{H}\right\}$ NMR spectroscopic results help to rationalise the trend observed for the flanking methyl protons (H-9) (Fig. 4). Since all other atoms on the xylyl rings remain unshifted, this suggests that electronic communication occurs via a through-space interaction between the methyl protons and lithium atoms. Some evidence of this is seen in the crystal structures, with weak $\mathrm{Li} \cdots \mathrm{H}-\mathrm{C}$ anagostic interactions observed in the solid state (Fig. S31 and S32†). In solution, this is further corroborated by two-dimensional ${ }^{7} \mathrm{Li}-{ }^{1} \mathrm{H}$ HOESY experiments, ${ }^{5,56}$ which reveal short ${ }^{7} \mathrm{Li} \cdots{ }^{1} \mathrm{H}$ contacts in $\mathbf{1 - 5}$ as evidenced by the intense cross-peak between the lithium signals and the H-9 protons (Fig. 5 and ESI, section $3 \dagger$ ).

Similar $\mathrm{Li} \cdots \mathrm{H}$ interactions have been reported for the monomeric [Mes ${ }^{*}-\mathrm{Li}$ ] species, whose ${ }^{6} \mathrm{Li}-{ }^{1} \mathrm{H}$ HOESY spectrum gave a cross-peak for the ortho tert-butyl protons, but not for the para tert-butyl protons. ${ }^{42}$ Moreover, the ortho groups (1.61 ppm) occurred at lower field than the para groups (1.56 ppm), owing to the electric field produced by lithium that deshields the protons within close proximity. ${ }^{42}$ Comparable findings have been described for other aryllithium complexes [Ar-Li] $\left(\mathrm{Ar}=\mathrm{Naph}, 2-\{t-\mathrm{BuS}\} \mathrm{C}_{6} \mathrm{H}_{4}\right) \cdot{ }^{57,58}$

From these results we suggest that the electronic influence of the para-substituents in complexes 1-5 is relayed through the central $m$-terphenyl ring, onto the lithium atoms, then through-space onto the nearby methyl protons. Evidence of similar through-space interactions within a $m$-terphenyl framework has already been reported for the $m$-terphenyl carboxylic 


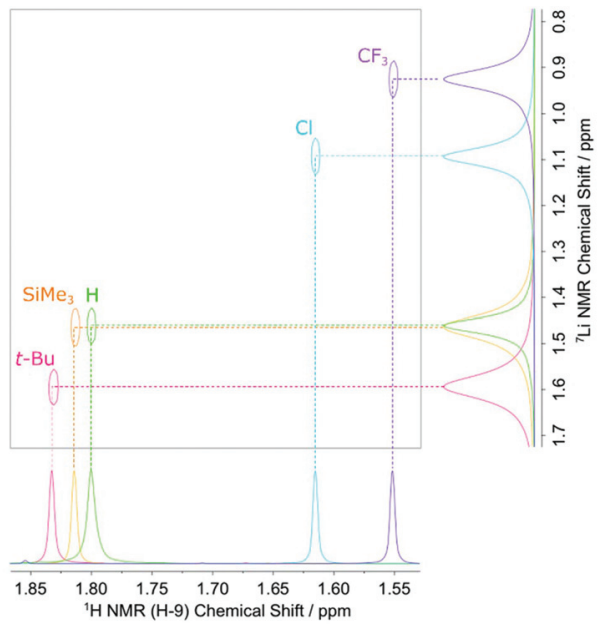

Fig. 5 Superimposed $2 \mathrm{D}{ }^{7} \mathrm{Li}-{ }^{1} \mathrm{H}$ HOESY spectra of the $m$-terphenyl lithium complexes $\left[\mathrm{R}-\mathrm{Ar}^{\#}-\mathrm{Li}_{2}\right.$ (1-5) showing strong cross-peaks between the flanking methyl protons, $\mathrm{H}-9$, and the ${ }^{7} \mathrm{Li}$ nuclei.

acids $\left(2,6-\mathrm{Ar}_{2} \mathrm{C}_{6} \mathrm{H}_{3}\right) \mathrm{COOH}\left(\mathrm{Ar}=4-\mathrm{R}_{-} \mathrm{C}_{6} \mathrm{H}_{4} ; \mathrm{R}=\mathrm{OMe}, \mathrm{Me}, \mathrm{H}, \mathrm{F}\right.$, $\mathrm{Cl}, \mathrm{Br}, \mathrm{C}\{\mathrm{O}\} \mathrm{Me}$ ) where para-substitution of the flanking aryl rings influences the $\mathrm{p} K_{\mathrm{a}}$ value, owing to through-space effects. ${ }^{59}$ In addition, the $m$-terphenyl silane $\left(2,6-\mathrm{Ar}_{2} \mathrm{C}_{6} \mathrm{H}_{3}\right)$ $\mathrm{SiMe}_{2} \mathrm{H}\left(\mathrm{Ar}=2,6-\mathrm{F}_{2} \mathrm{C}_{6} \mathrm{H}_{3}\right)$ possesses flanking aryl fluorine atoms that couple through-space to the $\mathrm{Si}-\mathrm{H}$ proton. ${ }^{60}$ To further investigate the origin of this effect we turned to computational analysis and DFT studies.

\subsection{Computational studies}

The calculation of NMR chemical shift parameters was carried out using the ReSpect program ${ }^{61-66}$ on structures obtained directly from the crystal structures, with optimisation of only the $\mathrm{H}$ atom locations at the PBE0 level; ${ }^{67,68}$ see ESI, section $\mathrm{S} 5 \uparrow$ for full computational details. NMR shielding constants were calculated using the KT2 density-functional approximation ${ }^{69}$ in the pcS- $n$ basis sets ${ }^{70}(n=1,2)$. This functional was specifically designed for the calculation of NMR shielding constants, as were the pcS- $n$ basis sets. Comparisons of the results for a range of other commonly used functionals (BLYP, BP86, PBE, PBE0, PP86) ${ }^{67,68,71-74}$ may be found in the ESI. $\dagger$

Tables summarising the calculated shifts for $\mathrm{H}-9$ and $\mathrm{Li}$ are given in the ESI, Tables S6 and S7. $\dagger$ Because of the relatively narrow chemical shift range, it is difficult to accurately model the trends shown in Fig. 3. Furthermore, both the H-9 and Li shifts are composed from absolute shielding constants containing large paramagnetic components (ESI, Table S5†). It is known that when the paramagnetic components are dominant, as in these cases, then density-functional methods often fail to achieve high accuracy. It is also known that densityfunctionals tend to be more accurate for ${ }^{1} \mathrm{H}$ and ${ }^{13} \mathrm{C}\left\{{ }^{1} \mathrm{H}\right\}$ NMR resonances than those for other nuclei. ${ }^{75}$ In line with these observations the calculated values for the ${ }^{7} \mathrm{Li}\left\{{ }_{1}^{1} \mathrm{H}\right\}$ NMR spectrum do not accurately capture the trend in Fig. 3. However, the trend for the ${ }^{1} \mathrm{H}$ NMR of the flanking $\mathrm{H}-9$ nuclei is more adequately reproduced, particularly for the KT2 functional in the larger pcS-2 basis. As shown in Fig. S34 of the ESI $\dagger$ the general trend for an upfield shift with increasing $\sigma_{\text {para }}$ is reproduced, see also Table S7. $\dagger$ Linear regression of the calculated ${ }^{1} \mathrm{H}$ NMR shifts for the H-9 nuclei as a function of $\sigma_{\text {para }}$ yields a fit with $R^{2}=0.92$, a somewhat steeper slope of -0.62 and a $y$-intercept of $+1.82 \mathrm{ppm}$. Given the challenges associated with the relatively narrow range of chemical shifts and large paramagnetic contributions for these nuclei, these results are in reasonable agreement with the experimental observations. However, based on these results, it seems likely that the counterintuitive trends observed in both the ${ }^{1} \mathrm{H}$ and ${ }^{7} \mathrm{Li}\left\{{ }^{1} \mathrm{H}\right\}$ NMR resonances is due to a large paramagnetic contribution to the shielding constant. Finally, we note that the more challenging ${ }^{7} \mathrm{Li}\left\{{ }^{1} \mathrm{H}\right\}$ NMR spectroscopy may provide a useful test case for the development of more refined density-functionals for NMR studies.

\section{Conclusions}

A series of para-substituted $m$-terphenyl lithium complexes [R$\left.\mathrm{Ar}^{\#}-\mathrm{Li}\right]_{2}\left(\mathrm{R}=t\right.$-Bu 1, $\mathrm{SiMe}_{3} 2, \mathrm{H} \mathrm{3}, \mathrm{Cl} 4, \mathrm{CF}_{3}$ 5) have been reported. Whilst crystallographically similar, and all displaying $\mathrm{Li} \cdots \mathrm{H}-\mathrm{C}$ anagostic contacts in the solid state, NMR spectroscopic studies reveal significant electronic differences at the metal centre. A linear correlation was observed between the Hammett constants of the para-substituent and the ${ }^{7} \mathrm{Li}$ and ${ }^{1} \mathrm{H}$ NMR shifts of the lithium atoms and flanking methyl protons $(\mathrm{H}-9)$. Electronic interaction between these atoms was confirmed by ${ }^{7} \mathrm{Li}-{ }^{1} \mathrm{H}$ HOESY measurements. In both cases, increasing the electron-withdrawing power of the parasubstituent results in a counterintuitive upfield peak shift. Computational analysis suggests this effect is due to an electric field generated about the lithium atoms, which is influenced by the para-substituent, and results in large paramagnetic and diamagnetic contributions to chemical shifts. While the observed trend in the ${ }^{1} \mathrm{H}$ NMR spectra of the H-9 protons was reproduced relatively well, it was difficult to accurately model the ${ }^{7}$ Li NMR spectroscopic trend by DFT.

\section{Conflicts of interest}

There are no conflicts to declare.

\section{Acknowledgements}

We acknowledge the EPSRC [grant number EP/R004064/1], the Leverhulme Trust [grant number RPG-2014-317], and the University of Nottingham for financial support of this research. We also thank the University of Nottingham Analytical Services Team for elemental analyses, mass spectrometry, and NMR spectroscopy measurements. We are also grateful for access to the University of Nottingham's Augusta High Performance Computing service. AMT is grateful for 
support from the European Research Council under H2020/ ERC Consolidator Grant “topDFT” (Grant No. 772259).

\section{References}

1 D. L. Kays, Organomet. Chem., 2010, 36, 56-76.

2 E. Rivard and P. P. Power, Inorg. Chem., 2007, 46, 1004710064.

3 L. J. Taylor and D. L. Kays, Dalton Trans., 2019, 48, 1236512381.

4 C. Ni and P. P. Power, in Metal-Metal Bonding, ed. G. Parkin, Springer Berlin Heidelberg, Berlin, Heidelberg, 2010, pp. 59-111.

5 B. Twamley, S. T. Haubrich and P. P. Power, Adv. Organomet. Chem., 1999, 44, 1-65.

6 J. A. C. Clyburne and N. McMullen, Coord. Chem. Rev., 2000, 210, 73-99.

7 D. L. Kays and A. R. Cowley, Chem. Commun., 2007, 10531055.

8 C. Stanciu, A. F. Richards, J. C. Fettinger, M. Brynda and P. P. Power, J. Organomet. Chem., 2006, 691, 2540-2545.

9 B. M. Gridley, A. J. Blake, A. L. Davis, W. Lewis, G. J. Moxey and D. L. Kays, Chem. Commun., 2012, 48, 8910-8912.

10 B. M. Gridley, T. J. Blundell, G. J. Moxey, W. Lewis, A. J. Blake and D. L. Kays, Chem. Commun., 2013, 49, 97529754.

11 B. Schiemenz and P. P. Power, Organometallics, 1996, 15, 958-964.

12 L. G. Perla, J. M. Kulenkampff, J. C. Fettinger and P. P. Power, Organometallics, 2018, 37, 4048-4054.

13 J. Su, X. W. Li, R. C. Crittendon and G. H. Robinson, J. Am. Chem. Soc., 1997, 119, 5471-5472.

14 R. J. Wehmschulte, W. J. Grigsby, B. Schiemenz, R. A. Bartlett and P. P. Power, Inorg. Chem., 1996, 35, 66946702.

15 T. J. Blundell, F. R. Hastings, B. M. Gridley, G. J. Moxey, W. Lewis, A. J. Blake and D. L. Kays, Dalton Trans., 2014, 43, 14257-14264.

16 B. Twamley, C. D. Sofield, M. M. Olmstead and P. P. Power, J. Am. Chem. Soc., 1999, 121, 3357-3367.

17 S. Wang, M. L. McCrea-Hendrick, C. M. Weinstein, C. A. Caputo, E. Hoppe, J. C. Fettinger, M. M. Olmstead and P. P. Power, J. Am. Chem. Soc., 2017, 139, 6586-6595.

18 S. Shah, M. C. Simpson, R. C. Smith and J. D. Protasiewicz, J. Am. Chem. Soc., 2001, 123, 6925-6926.

19 K. Ruhlandt-Senge, J. J. Ellison, R. J. Wehmschulte, F. Pauer and P. P. Power, J. Am. Chem. Soc., 1993, 115, 11353-11357.

20 B. Schiemenz and P. P. Power, Angew. Chem., Int. Ed. Engl., 1996, 35, 2150-2152.

21 R. C. Fischer, L. Pu, J. C. Fettinger, M. A. Brynda and P. P. Power, J. Am. Chem. Soc., 2006, 128, 11366-11367.

22 E. Rivard, R. C. Fischer, R. Wolf, Y. Peng, W. A. Merrill, N. D. Schley, Z. Zhu, L. Pu, J. C. Fettinger, S. J. Teat,
I. Nowik, R. H. Herber, N. Takagi, S. Nagase and P. P. Power, J. Am. Chem. Soc., 2007, 129, 16197-16208.

23 Z. Zhu, R. C. Fischer, B. D. Ellis, E. Rivard, W. A. Merrill, M. M. Olmstead, P. P. Power, J. D. Guo, S. Nagase and L. Pu, Chem. - Eur. J., 2009, 15, 5263-5272.

24 Y. Peng, R. C. Fischer, W. A. Merrill, J. Fischer, L. Pu, B. D. Ellis, J. C. Fettinger, R. H. Herber and P. P. Power, Chem. Sci., 2010, 1, 461-468.

25 P. Wilfling, K. Schittelkopf, M. Flock, R. H. Herber, P. P. Power and R. C. Fischer, Organometallics, 2015, 34, 2222-2232.

26 R. Wolf, C. Ni, T. Nguyen, M. Brynda, G. J. Long, A. D. Sutton, R. C. Fischer, J. C. Fettinger, M. Hellman, L. Pu and P. P. Power, Inorg. Chem., 2007, 46, 11277-11290.

27 S. Hino, M. M. Olmstead, J. C. Fettinger and P. P. Power, J. Organomet. Chem., 2005, 690, 1638-1644.

28 It should be noted that $t$-Bu-Ar${ }^{\#}$-I has been reported once before. However, it was only briefly mentioned as an intermediate in a multi-step reaction and very little characterisation data were given. Please see: S. Watanabe, K. Goto, T. Kawashima and R. Okazaki, Tetrahedron Lett., 1995, 36, 7677-7680.

29 M. Tian, L. Liu, Y. Li, R. Hu, T. Liu, H. Liu, S. Wang and Y. Li, Chem. Commun., 2014, 50, 2055-2057.

30 T. C. Bedard and J. S. Moore, J. Am. Chem. Soc., 1995, 117, 10662-10671.

31 D. Wrobel and U. Wannagat, J. Organomet. Chem., 1982, 225, 203-210.

32 A. Saednya and H. Hart, Synthesis, 1996, 1455-1458.

33 D. K. Miller, C. A. Bailey and R. E. Sammelson, Synthesis, 2015, 2791-2798.

34 A. Bondi, J. Phys. Chem., 1964, 68, 441-451.

35 Mercury User Guide and Tutorials, Cambridge Crystallographic Data Centre, 2018, pp. 306-307.

36 M. Brookhart, M. L. H. Green and G. Parkin, Proc. Natl. Acad. Sci. U. S. A., 2007, 104, 6908-6914.

37 T. D. W. Claridge, in High-Resolution NMR Techniques in Organic Chemistry, ed. T. D. W. Claridge, Elsevier, 2nd edn, 2009, vol. 27, pp. 303-334.

38 I. Keresztes and P. G. Williard, J. Am. Chem. Soc., 2000, 122, 10228-10229.

39 L. Allouche, A. Marquis and J. M. Lehn, Chem. - Eur. J., 2006, 12, 7520-7525.

40 C. Hansch, A. Leo and R. W. Taft, Chem. Rev., 1991, 91, 165-195.

41 D. Seebach, R. Hässig and J. Gabriel, Helv. Chim. Acta, 1983, 66, 308-337.

42 W. Bauer, W. R. Winchester and P. V. R. Schleyer, Organometallics, 1987, 6, 2371-2379.

43 S. Berger, U. Fleischer, C. Geletneky and J. C. W. Lohrenz, Chem. Ber., 1995, 128, 1183-1186.

44 H. Dahn, J. Chem. Educ., 2000, 77, 905-909.

45 J. T. B. H. Jastrzebski, G. van Koten, M. Konijn and C. H. Stam, J. Am. Chem. Soc., 1982, 104, 5490-5492.

46 M. H. P. Rietveld, I. C. M. Wehman-Ooyevaar, G. M. Kapteijn, D. M. Grove, W. J. J. Smeets, H. Kooijman, 
A. L. Spek and G. van Koten, Organometallics, 1994, 13, 3782-3787.

47 E. Wehman, J. T. B. H. Jastrzebski, J. M. Ernsting, D. M. Grove and G. van Koten, J. Organomet. Chem., 1988, 353, 133-143.

48 E. Wehman, J. T. B. H. Jastrzebski, J. M. Ernsting, D. M. Grove and G. van Koten, J. Organomet. Chem., 1988, 353, 145-155.

49 P. A. Scherr, R. J. Hogan and J. P. Oliver, J. Am. Chem. Soc., 1974, 96, 6055-6059.

50 H. Günther, D. Moskau, P. Bast and D. Schmalz, Angew. Chem., Int. Ed. Engl., 1987, 26, 1212-1220.

51 H. Günther, eMagRes, 2007, 1-21.

52 J. A. Ladd, Spectrochim. Acta, 1966, 22, 1157-1163.

53 J. Parker and J. A. Ladd, J. Organomet. Chem., 1969, 19, 1-7.

54 J. A. Ladd and J. Parker, J. Chem. Soc., Dalton Trans., 1972, 930-934.

55 W. Bauer, Magn. Reson. Chem., 1996, 34, 532-537.

56 W. Bauer, G. Müller, R. Pi and P. von Ragué Schleyer, Angew. Chem., Int. Ed. Engl., 1986, 25, 1103-1104.

57 W. Bauer, M. Feigel, G. Mueller and P. V. R. Schleyer, J. Am. Chem. Soc., 1988, 110, 6033-6046.

58 W. Bauer, P. A. A. Klusener, S. Harder, J. A. Kanters, A. J. M. Duisenberg, L. Brandsma and P. V. R. Schleyer, Organometallics, 1988, 7, 552-555.

59 C.-T. Chen and J. S. Siegel, J. Am. Chem. Soc., 1994, 116, 5959-5960.

60 P. Romanato, S. Duttwyler, A. Linden, K. K. Baldridge and J. S. Siegel, J. Phys. Org. Chem., 2014, 27, 277-283.

61 M. Repisky, S. Komorovsky, V. G. Malkin, O. L. Malkina, M. Kaupp and K. Ruud, with contributions from R. Bast, R. Di Remigio, U. Ekström, M. Kadek, S. Knecht, L. Konecny,
E. Malkin and I. Malkin Ondik, ReSpect 5.1.0, relativistic spectroscopy DFT program, http://www.respectprogram.org, 2019.

62 S. Komorovský, M. Repiský, O. L. Malkina, V. G. Malkin, I. Malkin Ondík and M. Kaupp, J. Chem. Phys., 2008, 128, 104101.

63 S. Komorovský, M. Repiský, O. L. Malkina and V. G. Malkin, J. Chem. Phys., 2010, 132, 154101.

64 S. Komorovsky, M. Repisky, E. Malkin, T. B. Demissie and K. Ruud, J. Chem. Theory Comput., 2015, 11, 37293739.

65 M. Repisky, S. Komorovsky, R. Bast and K. Ruud, in New Developments in NMR No. 6, ed. M. J. Karol Jackowski, The Royal Society of Chemistry, 2016, pp. 267-303.

66 M. Repiský, S. Komorovský, O. L. Malkina and V. G. Malkin, Chem. Phys., 2009, 356, 236-242.

67 J. P. Perdew, K. Burke and M. Ernzerhof, Phys. Rev. Lett., 1996, 77, 3865-3868.

68 C. Adamo and V. Barone, J. Chem. Phys., 1999, 110, 61586170.

69 T. W. Keal and D. J. Tozer, J. Chem. Phys., 2003, 119, 30153024.

70 F. Jensen, J. Chem. Theory Comput., 2008, 4, 719-727.

71 C. Lee, W. Yang and R. G. Parr, Phys. Rev. B: Condens. Matter Mater. Phys., 1988, 37, 785-789.

72 A. D. Becke, Phys. Rev. A, 1988, 38, 3098-3100.

73 J. P. Perdew, Phys. Rev. B: Condens. Matter Mater. Phys., 1986, 33, 8822-8824.

74 J. P. Perdew and W. Yue, Phys. Rev. B: Condens. Matter Mater. Phys., 1986, 33, 8800-8802.

75 A. M. Teale, O. B. Lutnæs, T. Helgaker, D. J. Tozer and J. Gauss, J. Chem. Phys., 2013, 138, 024111. 